\title{
The Propagation of Landslide-Generated Impulse Waves and Their Impacts on the Moored Ships: An Experimental Investigation
}

\author{
Ping Mu, ${ }^{1,2}$ Pingyi Wang $\mathbb{D}^{1,2}$ Linfeng Han, ${ }^{3}$ Meili Wang, ${ }^{4}$ Caixia Meng, ${ }^{1,2}$ Zhiyou Cheng, ${ }^{2,5}$ \\ and Haiyong $\mathrm{Xu}^{6}$ \\ ${ }^{1}$ School of River and Ocean Engineering, Chongqing Jiaotong University, Chongqing 400074, China \\ ${ }^{2}$ Key Laboratory of Hydraulic and Waterway Engineering of Ministry of Education, Chongqing Jiaotong University, \\ Chongqing 400074, China \\ ${ }^{3}$ School of Civil Engineering, Chongqing Jiaotong University, Chongqing 400074, China \\ ${ }^{4}$ School of Architecture and Urban Planning, Chongqing Jiaotong University, Chongqing 400074, China \\ ${ }^{5}$ School of Shipping and Naval Architecture, Chongqing Jiaotong University, Chongqing 400074, China \\ ${ }^{6}$ Key Laboratory of Engineering Sediment, Tianjin Research Institute for Water Transport Engineering of Ministry of Transport, \\ Tianjin 300456, China
}

Correspondence should be addressed to Pingyi Wang; py-wang@163.com

Received 14 July 2019; Revised 31 January 2020; Accepted 15 February 2020; Published 12 May 2020

Academic Editor: Zhongguo John Ma

Copyright ( $\odot 2020$ Ping Mu et al. This is an open access article distributed under the Creative Commons Attribution License, which permits unrestricted use, distribution, and reproduction in any medium, provided the original work is properly cited.

\begin{abstract}
The effective prevention and reduction of the hazardous impact of landslide-generated impulse waves on the moored ships are crucial for the sustainable operation of the reservoirs. Although the investigations of landslide-generated impulse waves have been widely studied in the past decades, few efforts involved their impacts on the moored ships. The authors in this paper specifically examine the hazardous impact of the impulse waves on the moored ships by applying the physical experiments. Considering that the impulse wave was an external force acting on the mooring line, the impulse wave generation, propagation, and its impact on the moored ships are hence explored in detail. The results indicate that the impact of impulse waves on the moored ships was mainly due to the first wave amplitude and height, and an exponential function relationship between the relative wave height and wave crest amplitude was revealed. Furthermore, the attenuation of the maximum wave crest amplitude was approximated by a power exponential function. On this basis, the mooring tension could be calculated based on the linear relationship between the mooring tension and wave height. Ultimately, the safety of the moored ships in the port can be evaluated.
\end{abstract}

\section{Introduction}

As a worldwide secondary natural hazard, the impulse waves erupting in reservoirs have caused a range of catastrophic disasters and resulted in large economic losses. In general, impulse waves are generated by landslides and also referred to as landslide tsunamis $[1,2]$. With great energy, the hazard of landslide-generated impulse waves can cause vast losses of life and properties, the destruction of critical infrastructure in wharf, and massive damage even overturns to the vessels. If such tremendous waves overtop the dam, the consequences are fatal for the downstream areas. In this regard, we take the well-known Vajont landslide occurring in Italy in 1963 as a typical case, which killed almost 2000 persons and completely destroyed the downstream city of Longarone [3]. In this situation, to gain the desired sustainable operation of the reservoir, it is a common strategy for any country to pursue effective prevention and reduction of this natural hazard.

Hence, to solve the problem, the landslide-generated impulse waves occurring in reservoirs have attracted a wide range of international researchers in recent decades [4-7]. However, looking carefully at these existing studies, more attention has been paid to the characteristics of the hazard and the disaster losses, especially in the number of casualties 
and economic losses based on the postdisaster investigation $[4,8,9]$, while the moored ships in the port have received little attention. Thus, a research gap remains in the extant literature; namely, the moored ships against impulse waves have been ignored.

Against this unique background, as the largest hydroelectricity project in the world, the Three Gorges Reservoir (TGR) constructed on Yangtze River in China has been plagued with the serious natural hazard of landslide-generated impulse waves since its completion and delivery in 2003 [10]. Meanwhile, the water traffic is extremely heavy. For instance, the survey organized by the Yangtze River waterway administration indicated that about 138 million tons of cargo was transported through the reservoir in 2017 [11]. In other words, at any time, a large number of ships are moored in wharf. More importantly, in recent years some related catastrophic events have occurred [4]. Given these situations and the reported research gap, taking TGR as a typical case, undertaking the research of the hazardous impact of impulse waves on the moored ships is not only important but also necessary.

On the abovementioned basis, this study aims to examine the hazardous impact of impulse waves on the moored ships in TGR. We consider that the impact is largely constrained by the mooring tension of the line at the quay, whilst the damage of impulse waves is mainly due to wave height, especially the first waves $[12,13]$. Additionally, the induced impulse waves will gradually attenuate over propagation distance $[7,12,14]$. Therefore, the detailed objectives of this paper are as follows: (1) to mimic impulse wave generation and explore its propagation and (2) to reveal the relationship between the mooring tension and impulse wave height; to the best of our knowledge, very few studies explored the hazardous impact of impulse waves in reservoirs on the moored ships in China and elsewhere. Hence, we innovate in the field of impulse waves and its disaster prevention by considering the moored ships in TGR.

The remainder of this paper is structured as follows. We describe the research methodology in the next section. Section 3 presents the results and discussion. Conclusions are drawn in the final section.

\section{Methodology}

2.1. Research Design. As emphasized by Huang et al. [15], due to the unique characteristics (e.g., short duration and sudden occurrence), the induced impulse waves are little on field measurements. To solve data constraints, in line with previous studies $[7,16-22]$, we select physical model to simulate and induce impulse waves and obtain the complicated data. On this basis, we analyze these data to fulfill the above research objectives. Thus, the following two-stage research design is planned, just exhibited in Figure 1.

\subsection{Experimental Set-Up}

2.2.1. The Three-Dimensional Basin. As mentioned in Section 2.1, the experimental study is selected to conduct this work. In this background, a physical model was built at $1: 70$ scale (for details also see Section 2.5), which was typically curved reach in the upper Yangtze River and generalized from the prototype of Jiangnan tuokou wharf reach. Figure 2 shows the schematic layout of the three-dimensional (3D) basin.

The total length of the basin was $48 \mathrm{~m}$; the upstream and downstream straight were $28 \mathrm{~m}$ and $13 \mathrm{~m}$, respectively. The radius of curvature for the intermediate portion was $7 \mathrm{~m}$. The basin sides were covered with a concrete paste so as to enhance the roughness and make the model more realistic. The cross-section of the basin was trapezoidal, as shown in Figure 3, the top width was $8 \mathrm{~m}$, and the bottom was $2.94 \mathrm{~m}$. The slopes in the concave and convex banks were $33^{\circ}$ and $20^{\circ}$, respectively.

2.2.2. The Wave-Making System. The waves were generated by a gravity type wave maker at the concave bank of the basin (see Figure 2). The wave-making system consisted of landslide, chute, wire mesh gate and chain hoist, and so on, as described in Figure 4. This chute allowed for predefining the slide geometry, including a slide width of $0.50 \mathrm{~m}, 1.00 \mathrm{~m}$, and $1.50 \mathrm{~m}$, and a landslide front edge allowing it to reach different still water depths, as well as a landslide impact angle with any value. A flexible wire mesh gate was placed in the front of the sliding chute to restrain the concrete blocks before the trials. When everything was ready, for instance, the water was still and the measuring equipment had been already debugged, the motion of landslide was triggered and accelerated due to gravity into the water body after suddenly manual release for the wire mesh gate. Clearly, the landslide is of great importance for the wave-making system; a special introduction hence will be presented in the following section.

2.2.3. The Landslide. Considering the similarity and deformability reported by Yavari-Ramshe, and Ataie-Ashtiani. [23], the landslide was modeled by the granular concrete blocks containing five various geometric sizes (labelled as A1, A2, A3, A4, and A5) as illustrated in Table 1. Compared with other granular materials (e.g., $\mathrm{PP}-\mathrm{BaSO}_{4}$ ) in [24], the landslide materials of present experiments were more similar to the happening or potential landslides in TGR.

Tested landslide models with nine different sizes, including a constant landslide length of $1.00 \mathrm{~m}$, a landslide width of $0.50 \mathrm{~m}, 1.00 \mathrm{~m}$, and $1.50 \mathrm{~m}$, and a landslide thickness of $0.20 \mathrm{~m}$, $0.40 \mathrm{~m}$, and $0.60 \mathrm{~m}$, were carried out by adjusting the sliding cute geometrical shape (see Figure 4). As reported by Wiegel [19], the landslide length with a constant $l=1.00 \mathrm{~m}$ was deemed to be appropriate based on the result that the landslide length has a slight influence on the primary wave. The landslide was composed of concrete blocks with an equal number of A1, A2, A3, A4, and A5. Based on the permutation and combination of concrete blocks, landslides were classified into nine classes encompassing S1, S2, S3, S4, S5, S6, S7, S8, and S9 to simulate and induce the impulse waves in our experiments; the detailed sizes and volumes of the landslides are shown in Table 2 . 


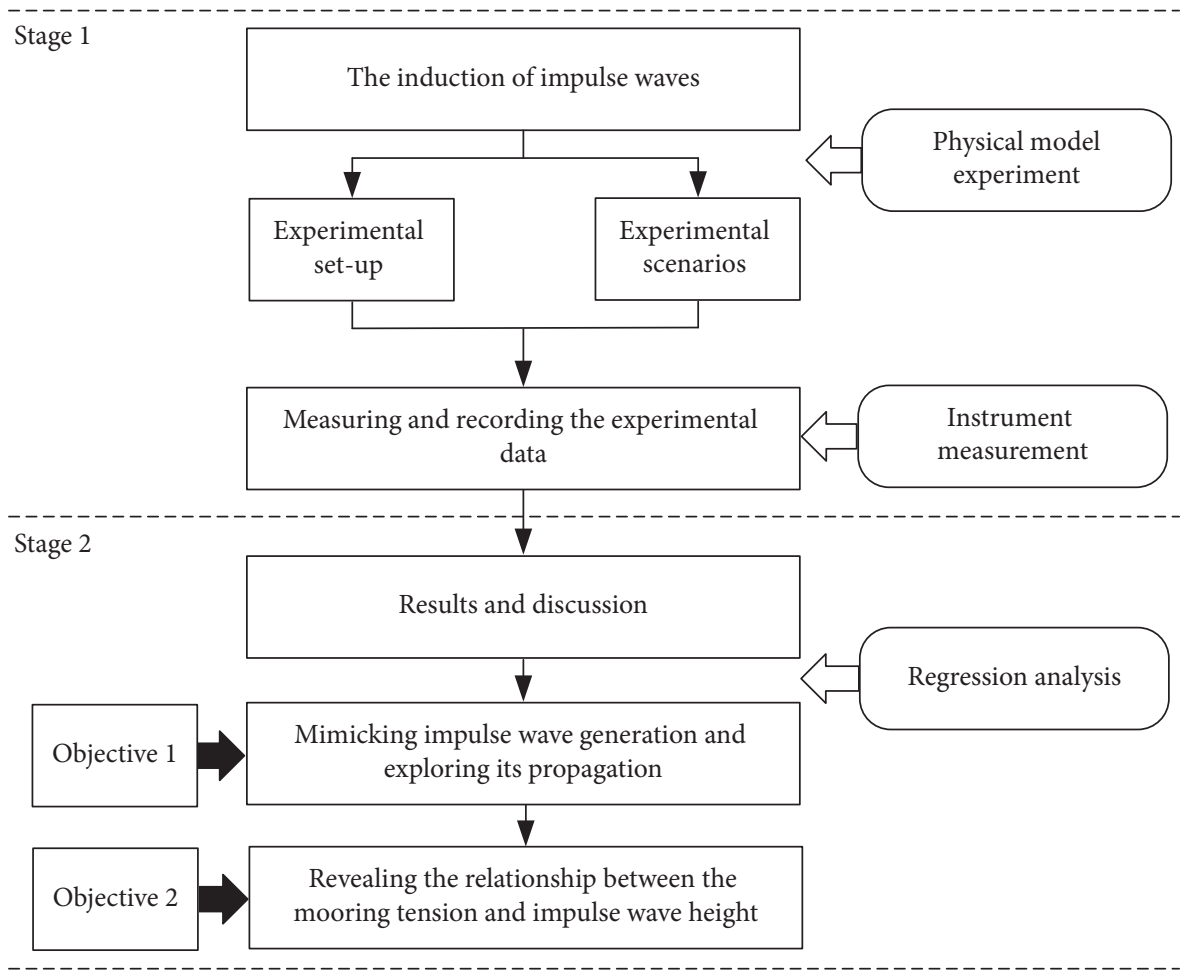

FIGURE 1: The research design of this paper.

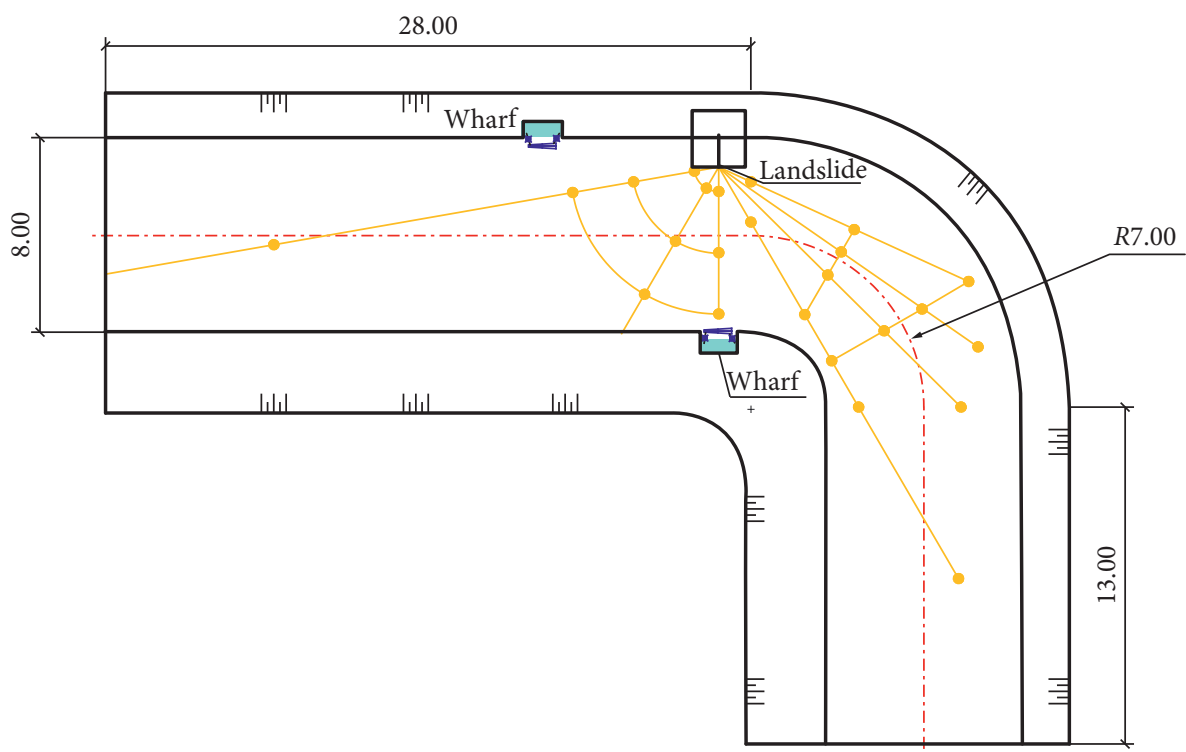

\footnotetext{
Moored cargo ships

Mooring tension sensors

Wave gauge sensors
}

Figure 2: Schematic diagram of model experimental layout; geometrical measurements were in m.

2.2.4. The Wharf and Cargo Ship. The type of wharf used in the present study is "high-pile," which is one of the most popular geometrical wharf designs in TGR as well [12]. Its structure is assumed as "rigid," fixed in the basin. There was only one berth with two mooring bollards in the experimental model, and the length and width of the wharf were
$1.50 \mathrm{~m}$ and $0.43 \mathrm{~m}$, respectively. Cylinder piers with the diameter of $2.28 \mathrm{~cm}$, line spacing $10.00 \mathrm{~cm}$, were made by plastic pipes. In addition, the dock panel, beams, and stringers were all plastic, as illustrated in Figure 5. Given that the impulse waves propagated along with all directions, so two wharves were set: one was located the same shore of the 


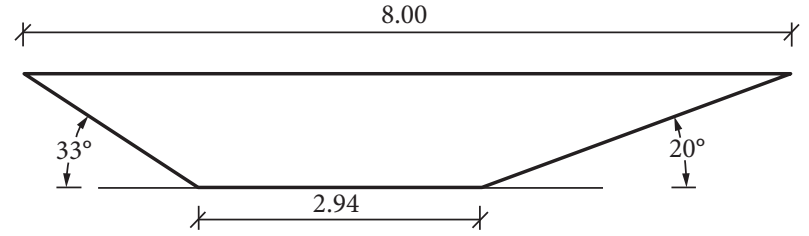

FIgURE 3: Cross-section of the basin; geometrical measurements were in $\mathrm{m}$.

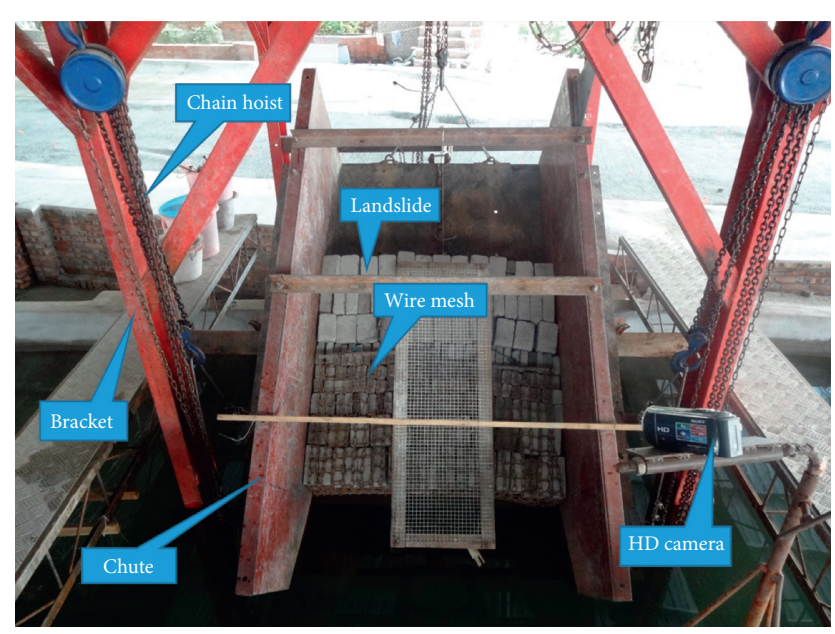

Figure 4: The wave-making system.

TABLE 1: Sizes of concrete blocks.

\begin{tabular}{lccc}
\hline Block number & Length $(\mathrm{cm})$ & Width $(\mathrm{cm})$ & Thickness $(\mathrm{cm})$ \\
\hline A1 & 18 & 12 & 6 \\
A2 & 12 & 8 & 4 \\
A3 & 9 & 6 & 3 \\
A4 & 6 & 4 & 2 \\
A5 & 3 & 2 & 1 \\
\hline
\end{tabular}

TAвLE 2: Sizes and volume of landslides.

\begin{tabular}{lcccc}
\hline $\begin{array}{l}\text { Landslide } \\
\text { number }\end{array}$ & $\begin{array}{c}\text { Length } \\
(\mathrm{m})\end{array}$ & $\begin{array}{c}\text { Width } \\
(\mathrm{m})\end{array}$ & $\begin{array}{c}\text { Thickness } \\
(\mathrm{m})\end{array}$ & Volume $\left(\mathrm{m}^{3}\right)$ \\
\hline S1 & 1.0 & 0.5 & 0.2 & 0.1 \\
S2 & 1.0 & 1.0 & 0.2 & 0.2 \\
S3 & 1.0 & 1.5 & 0.2 & 0.3 \\
S4 & 1.0 & 0.5 & 0.4 & 0.2 \\
S5 & 1.0 & 1.0 & 0.4 & 0.4 \\
S6 & 1.0 & 1.5 & 0.4 & 0.6 \\
S7 & 1.0 & 0.5 & 0.6 & 0.3 \\
S8 & 1.0 & 1.0 & 0.6 & 0.6 \\
S9 & 1.0 & 1.5 & 0.6 & 0.9 \\
\hline
\end{tabular}

landslide (in concave bank) and the other one was placed on the opposite (in convex bank), both $6.37 \mathrm{~m}$ far from the location of the landslide occurrence.

As stated by Chen [25], approximately $88.98 \%$ of the ships operating in TGR are cargo ships, whilst about $90.79 \%$ of these ships are under 3000 DWT. Given this condition, the iron model ships (see Figure 5) were designed based on a

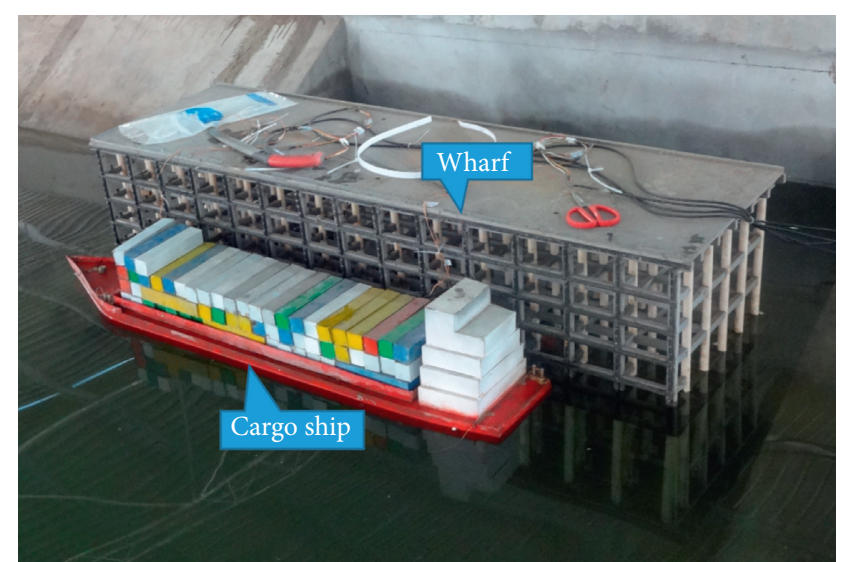

FIGURE 5: The experimental wharf and moored cargo ship in fullcargo condition.

prototype of 3000 DWT cargo ship. Primary parameters of the real and model ship are shown in Table 3. There were some conditions of the moored ships: light ship, half cargo, and full-cargo condition. Moreover, the most hazardous scene was that cargo ship is in full-cargo condition; hence, we only focused on the worst-case scenario.

The ships were moored on the port side by nylon ropes in the stern and head line, which were at an angle of $30^{\circ}$ with the wharf front (see Figure 6). For the cargo ship in convex bank, the incident angle of the impulse waves was about $90^{\circ}$, because the impulse waves propagated towards the wharf. For the cargo ship in concave bank, the incident impulse waves angle was parallel to the quay because the waves flowed along it.

2.3. Experimental Scenarios. The experimental tests were carried out for 81 different scenarios of landslide-generated impulse waves by varying the parameters of the thickness $(s)$, width $(w)$, angle of landslide $(\alpha)$, and the still water depth in the basin $(h)$. Landslide volume and angle may be changed by adding and removing concrete blocks and by varying the initial location of the chute, respectively. In line with the dispatching practice of reservoir flood in TGR, $145.00 \mathrm{~m}$, $155.00 \mathrm{~m}$, and $175.00 \mathrm{~m}$ were selected as the simulated water levels [15]. Based on our field surveys of the cross-section and the bottom elevation of the prototype, the water depths in the physical model corresponding with these three usual water levels can be calculated according to geometric similarity to be $0.74 \mathrm{~m}, 0.88 \mathrm{~m}$, and $1.16 \mathrm{~m}$ (for details, see also Section 2.5). In addition, field investigation also reported that the distribution of landslide angle in TGR was from $20^{\circ}$ to $60^{\circ}$ and the average value was $36^{\circ}$. Hence, in the experiment, the angles were limited to $20^{\circ}, 40^{\circ}$, and $60^{\circ}$.

2.4. Methods of Measuring and Recording Data. An HD camera (see Figure 4) was placed on a tripod to record the characteristic of the sliding process in a video format. Using MATLAB software, a series of images can be extracted from the video to calculate the landslide impact velocity. 
Table 3: Primary parameters of the real and model ship.

\begin{tabular}{lcc}
\hline Parameter & Real ship & Model ship \\
\hline Length $(\mathrm{m})$ & 90 & 1.28 \\
Depth $(\mathrm{m})$ & 4 & 0.057 \\
Width $(\mathrm{m})$ & 16 & 0.228 \\
Designed draft $(\mathrm{m})$ & 3.3 & 0.047 \\
Block coefficient & 0.8 & 0.8 \\
Loaded displacement $(\mathrm{t} / \mathrm{g})$ & $3000 \mathrm{t}$ & $8700 \mathrm{~g}$ \\
\hline
\end{tabular}

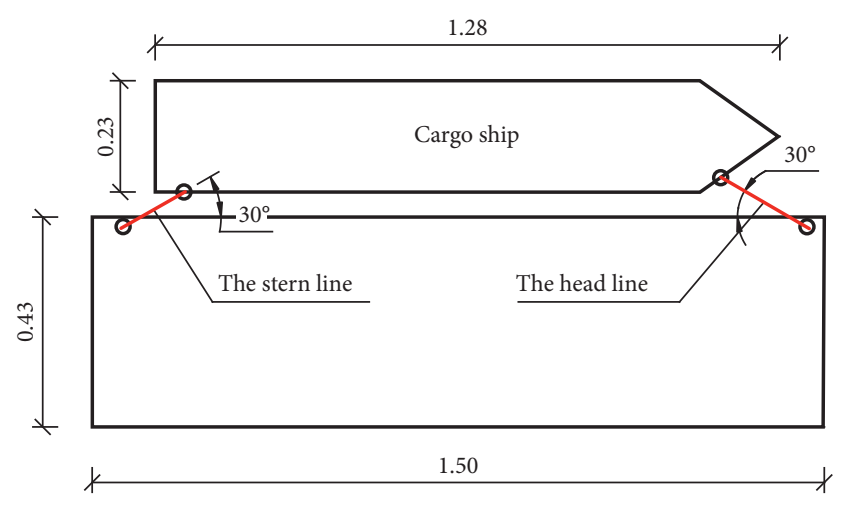

FIgURE 6: Mooring condition of cargo ship.

As exhibited in Figure 2, twenty-four wave gauges were placed in the basin for measuring the water surface displacement. Each sensor was partially submerged and corresponds to a channel with an identification number from 1 to 24 which returned voltage values. They could be converted to water level values at the designated spots by UBL-2 Ultrasonic Water Level/Wave Acquisition Analyzer (UWL/ WLAA) developed by Southwest Water Transport Engineering Research Institute in China. The UWL/WLAA has been widely used in similar experimental measurements on account of high reliability and accuracy $[14,26]$.

Tension sensors (model number: BE120-2AA) were used for measuring the mooring tension of the lines restricting the moored cargo ship. There were two lines attached to the head and stern of the ship, with enough strength to contend against the impact force of waves at the wharf (see Figure 6). As a result, four elastic flaky sensors with an identification number from 1 to 4 which returned voltage values were used, as shown in Figure 2. These voltage values could be converted to the mooring tension through Dynamic Signal Test Analysis System (DSTAS). The signal acquisition frequency was 500 Hertz. Before the experiment, extensive efforts of calibration had been done. We acquired the mass-voltage curve by adding load from $0 \mathrm{~g}$ to $1200 \mathrm{~g}$ on the step of $100 \mathrm{~g}$. The same calibration procedure had been repeated many times until satisfactory results could be obtained. For example, we had verified 3 times the elastic strain of Ch.1; the corresponding mass-voltage curves were depicted (see Figure 7), and the average value was finally adopted. Based on the mass-voltage curve of the materials and the relationship between mass and weight, the ultimate mooring tension-voltage value curve could be derived.

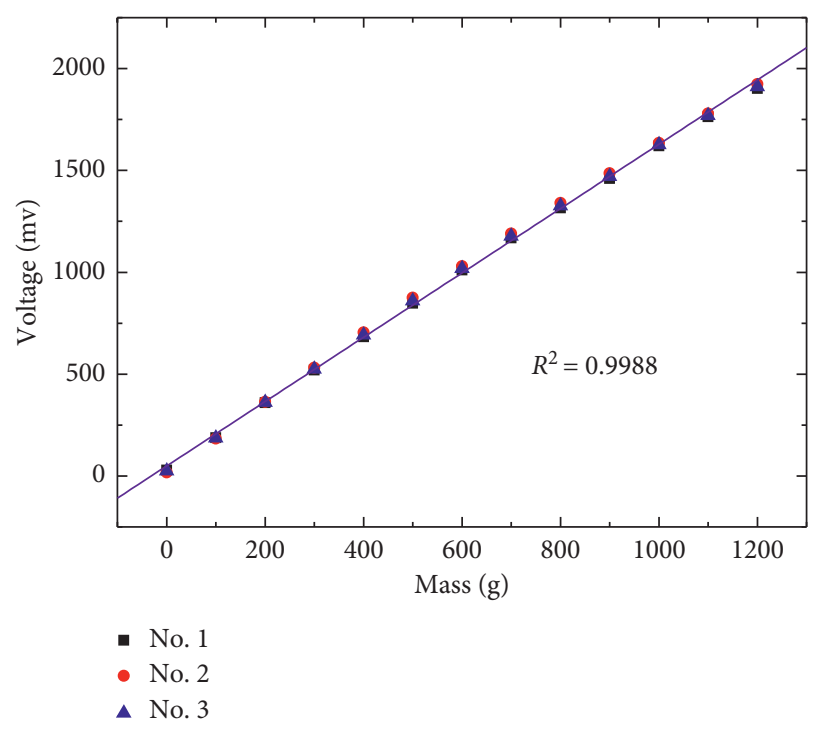

FIgURE 7: The force-voltage curve of elastic strain in Ch.1.

2.5. Scale Analysis. Additionally, a good physical model that can represent its real world prototype should satisfy geometric similarity, kinematic similarity, and dynamic similarity [27]. According to the Froude similitude, the similitude ratios of all parameters in present study are shown in Table 4.

There was a geometric similarity between the experimental and real world scenarios in the present tests, and geometric scale $\lambda_{l}=70$. In the experiments, the landslide length, width, and thickness were $1.0 \mathrm{~m}, 0.5 \mathrm{~m} \sim 1.5 \mathrm{~m}$, and $0.2 \mathrm{~m} \sim 0.6 \mathrm{~m}$, respectively, representing the landslides with the length of $70 \mathrm{~m}$, width of $35 \mathrm{~m} \sim 105 \mathrm{~m}$, and thickness of $14 \mathrm{~m} \sim 42 \mathrm{~m}$; the corresponding volume was $490 \sim 4410 \mathrm{~m}^{3}$ in the real world. For water levels $145 \mathrm{~m}, 155 \mathrm{~m}$, and $175 \mathrm{~m}$ in the Jiangnan tuokou wharf reach, water depths were $51.8 \mathrm{~m}$, $61.6 \mathrm{~m}$, and $81.2 \mathrm{~m}$, respectively. In the tests, the water depths were $0.74 \mathrm{~m}, 0.88 \mathrm{~m}$, and $1.16 \mathrm{~m}$ with the scale factor $\lambda_{l}=70$. For the slide impact velocity, the scale factor $\lambda_{v}=\lambda_{l}^{1 / 2}=\sqrt{70}$ based on the kinematic similarity criterion, and the landslide impact velocity ranged from $0.55 \mathrm{~m} / \mathrm{s}$ to $2.68 \mathrm{~m} / \mathrm{s}$ in the experiments, corresponding to the velocity $4.6 \mathrm{~m} / \mathrm{s} \sim 22.38 \mathrm{~m} /$ $\mathrm{s}$ in the real world. There was a high match between tests and real scenarios in TGR. Furthermore, the slide Froude number as a crucial dimensionless parameter that ranged from 0.178 to 0.993 based on $F_{r}=v_{s} / \sqrt{g h}$, where $v_{s}$ was the landslide impact velocity and $h$ was the still water depth.

The dynamic similarity of the physical model was based on the Froude similitude. To exclude the scale effect, the Weber number We and Reynolds number Re were used to estimate the influence of surface tension and the fluid viscosity effects, respectively [24]. In our experiments, Re and We were equal or greater than 300,000 and 5000, respectively; therefore the scale effects were negligible [28]. So the Froude similitude was suitable for the landslide-generated impulse wave phenomena, and the force scale $\lambda_{F}=\lambda_{l}^{3}=70^{3}$. Hence, the mooring tension in the real world $F_{P}=\lambda_{F} F_{M}$, where the $F_{M}$ is the mooring tension in the experiment. 
Table 4: Similitude ratios according to the Froude similitude.

\begin{tabular}{lcc}
\hline Parameter & Fundamental dimension & Similitude ratio \\
\hline Length & $(\mathrm{L})$ & $\lambda_{l}$ \\
Time & $(\mathrm{T})$ & $\lambda_{l}^{1 / 2}$ \\
Velocity & $\left(\mathrm{LT}^{-1}\right)$ & $\lambda_{l}^{1 / 2}$ \\
Force & $\left(\mathrm{MLT}^{-2}\right)$ & $\lambda_{l}^{3}$ \\
\hline
\end{tabular}

\section{Results and Discussion}

3.1. Impulse Wave Generation and Propagation. By using the high speed camera, we clearly observed the entire process of the wave generation and propagation in the near field, as shown in Figure 8.

The figure shows that the first wave crest was generated and propagated away from the near field, whilst the first wave trough formed at the impact zone. Closely followed by the second wave crest and trough, after that, the water surface fell once and rose again, and the trailing wave train followed. In addition, observations also indicate that the first wave amplitude and height were the most significant and effective conditioning factors for the hazardous impact of impulse waves induced by landslides. In this regard, such finding is considered to be consistent with previous studies $[14,26]$. Therefore, the first wave amplitude, height, and attenuation will be analyzed and discussed in the following sections.

3.1.1. Maximum Wave Amplitude. By analyzing the data recorded by 24 wave gauges of all the 81 experimental scenarios, it is not hard to find a common phenomenon that the impulse waves induced by landslide were nonlinear wave, and the wave crest amplitude was larger than the wave trough amplitude. Moreover, the first wave crest amplitude was the largest one, which is considered to be consistent with previous studies $[29,30]$. Take Scenario 47 as an example, the water surface displacement recorded by six random wave gauges is plotted in Figure 9.

Apart from the aforementioned descriptive results, an expression for the maximum wave crest amplitude would be further explored. As emerged from previous empirical equation derived by Fritz et al. [29], the landslide velocity, landslide thickness, and still water depth were important factors governing the maximum crest amplitude. Nevertheless, their tests were conducted in a two-dimensional flume; the effect of landslide width was neglected. In this study, landslide width was an important factor governing the momentum transfer process. Hence, a modified empirical equation of the maximum crest amplitude was obtained based on our test data, as presented in

$$
\frac{a_{c m}}{h}=4.65 F_{r}^{1.18} S^{0.77} B^{0.15},
$$

where $a_{c m}$ is the maximum crest amplitude in the impulse wave generation zone; $S$ and $B$ are the relative landslide thickness and width, respectively; and $h$ is the still water depth.

Unfortunately, the factor of landslide angle was not considered in the revealed expression, because the influence of landslide angle on the first wave amplitude was controversial. For example, Huber and Hager [31] thought that the maximum wave crest amplitude increased with the impact angle increase, but Panizzo et al. [2] presented a contrary view that the wave crest amplitude decreased with the increase of landslide angle. In this study, the landslide with an angle $40^{\circ}$ induced the highest wave crest amplitude when all other things were equal. It was coincident with the finding by Tang et al. [32], who reported that when the slide angle was in the lower band, the primary wave crest amplitude increased with the increase of the impact. However, as the landslide angle exceeded a threshold value, the wave crest amplitude decreased with the increase of the slide angle. In their work, the threshold value was about $37.5^{\circ}$. In general, the landslide angle had little effect on the maximum crest amplitude in our experiment, so it would be neglected.

3.1.2. Maximum Wave Height. In this section, wave height will be explored. For regular linear waves, the wave trough amplitude is strictly equal to the wave crest amplitude; namely, the wave height is twice the crest amplitude. However, for the impulse wave in present tests, the maximum trough amplitude always was less than or equal to the maximum crest amplitude. This is consistent with previous observations by Fritz et al. [29], who reported that the maximum crest amplitudes always matched or exceeded the maximum trough amplitudes. The same phenomenon has also been presented in the study of Xue et al. [33], who suggested that when $0.07<a_{c m} / h<1.05$, the expression for the relative maximum wave height could be addressed as

$$
\frac{H_{m}}{h}=1.07\left(\frac{a_{c m}}{h}\right)^{0.81} \text {. }
$$

Herein, $H_{m}$ is the maximum wave height in the impulse wave generation zone.

We further examined the applicability of existing empirical equation developed by Xue with our experimental data and found that the calculated value was less than the experimental value (see Figure 10). This phenomenon may be mainly attributed to the physical model; the tests conducted by Xue were in two-dimensional flume and the side wall restrained the impulse wave propagation. However, in this three-dimensional basin, the wall side had little effect on the propagation of the impulse waves. Given that situation, (2) was deemed to be basically applicable for this work. On this basis, referring to Xue the relative maximum wave height as a function of the relative maximum wave crest amplitude could be derived based our experimental data, as shown in

$$
\frac{H_{m}}{h}=1.39\left(\frac{a_{c m}}{h}\right)^{0.77} .
$$

\subsubsection{Maximum Wave Crest Amplitude Attenuation.} Subsequently, the attenuation of maximum wave amplitude and wave height will be revealed. Considering that wave height and wave crest amplitude have been linked through 


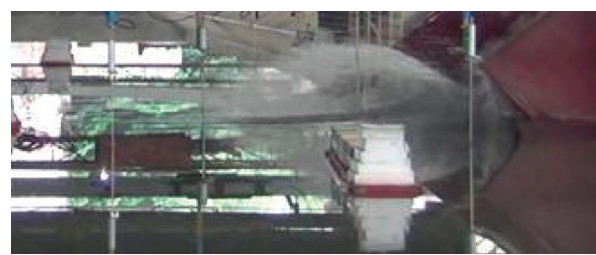

(a)

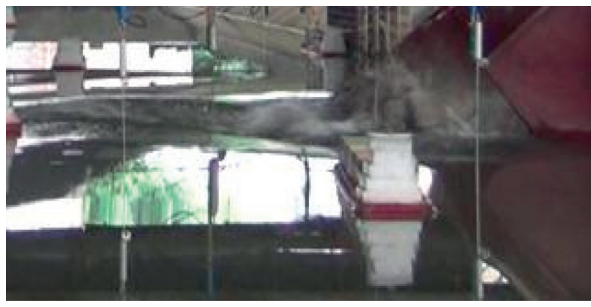

(c)

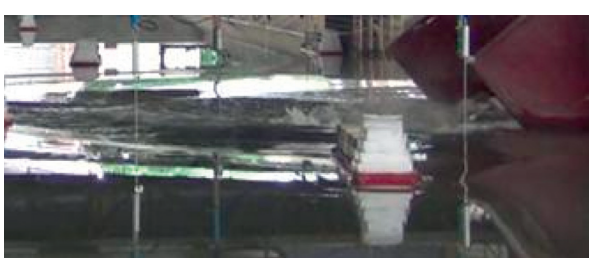

(b)

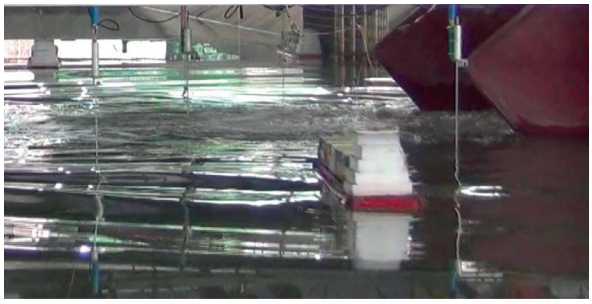

(d)

Figure 8: The process of impulse waves formation. (a) The first wave crest. (b) The first wave trough. (c) The following wave crest and trough. (d) Trailing wave train.
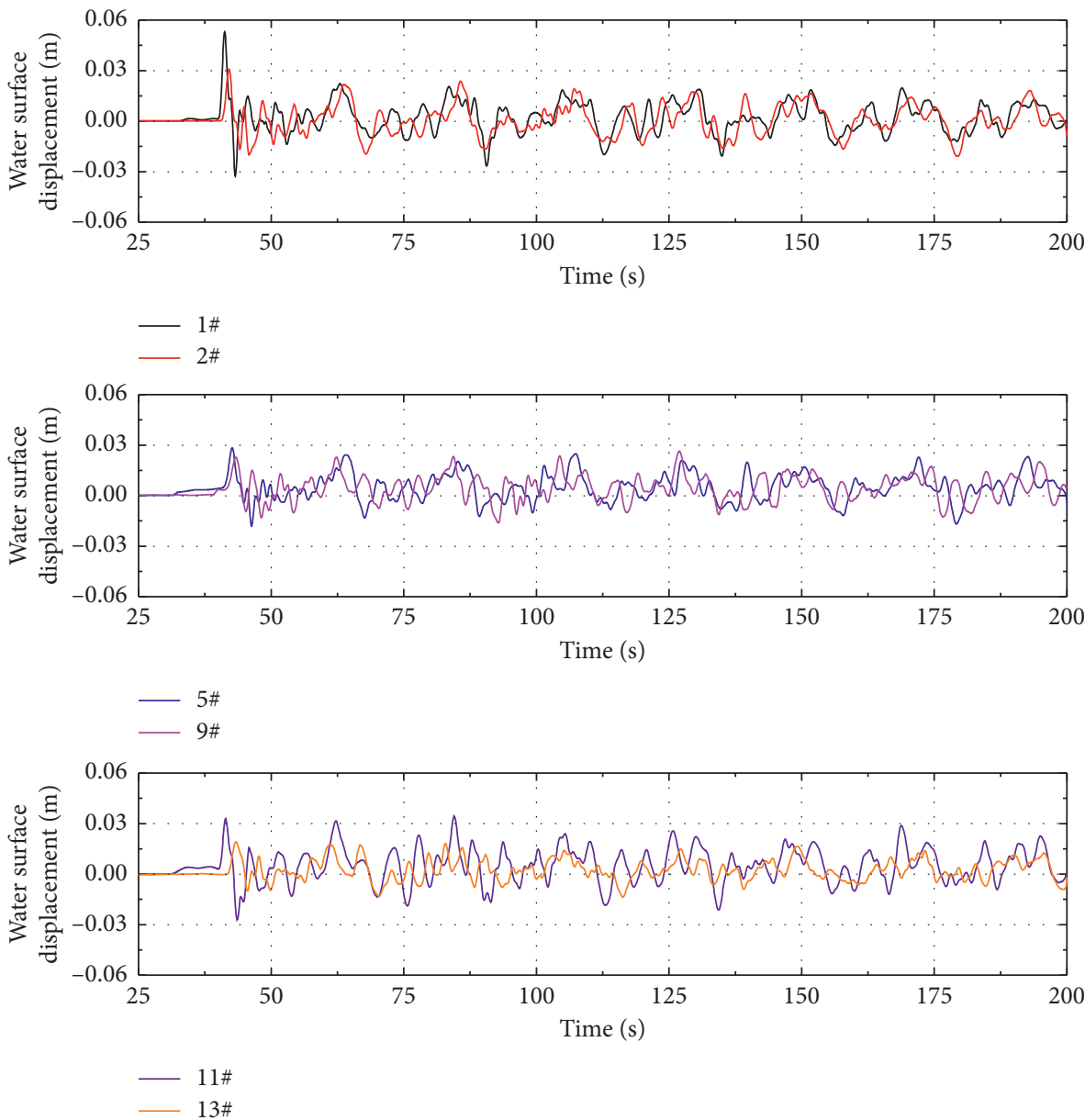

Figure 9: The water surface displacement from Scenario 47 with $l=1.0 \mathrm{~m}, w=0.5 \mathrm{~m}, s=0.4 \mathrm{~m}, h=0.88 \mathrm{~m}$, and $\alpha=60^{\circ}$.

(3), only the maximum wave crest amplitude was analyzed in this section.

In line with the findings of Evers and Hager [34], our results report that the wave amplitude and energy of the induced waves were maximal in near field and decayed gradually when they spread around. Moreover, it is found that the initial impulse waves attenuated sharply in the nearfield region and then gradually propagated to the far-field 


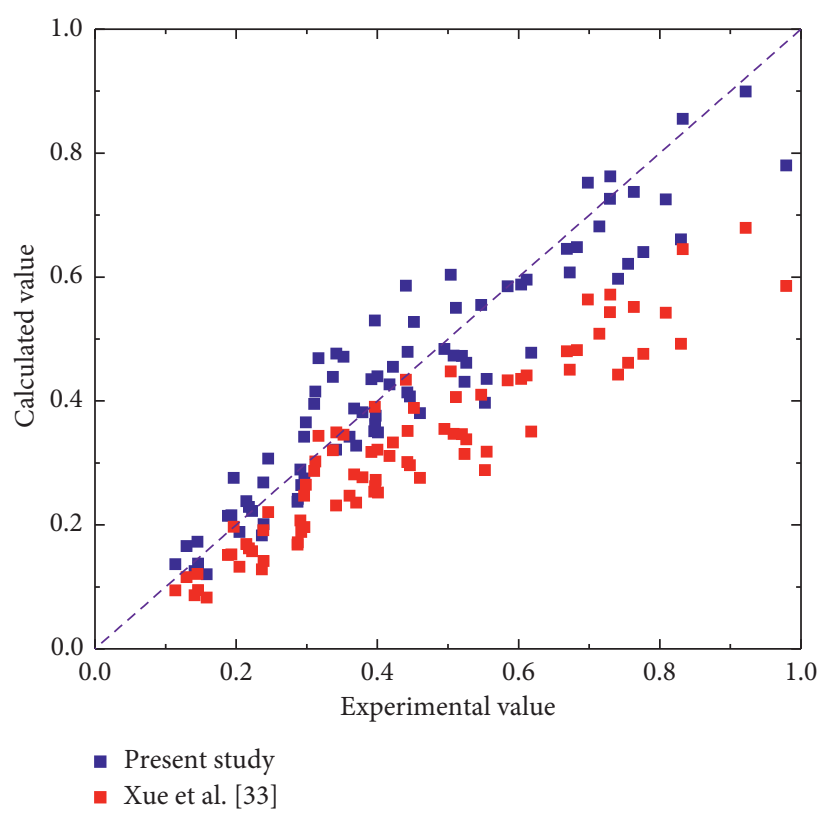

FiguRE 10: Experimental and calculated values of the impulse wave height.

region and attenuated slowly. However, experimental results indicate that there were no exactly the same patterns of the attenuation coefficient in the meandering and straight reaches. For the straight reaches, as shown in Figure 11, multiple regression analysis was adopted to obtain the wave crest amplitude attenuation based on all the experimental scenarios.

Figure 11 reveals that the attenuation of the wave crest amplitude only depended on the propagation distance $r_{x}$. Obviously, the wave crest amplitude was well featuring a power exponent attenuation, as seen in

$$
\frac{a_{c x}}{a_{c m}}=\left(\frac{r_{x}}{r_{c m}}\right)^{-1.3}
$$

where $a_{c x}$ was the wave crest amplitude in the propagation distance $r_{x}$ and $r_{c m}$ was the distance of the location between the place where landslide fell into water and the maximum wave crest amplitude reached.

Similarly, Figure 12 reveals the attenuation of the wave crest amplitude in meandering reaches. Obviously, the attenuation relied not only on the propagation distance $r_{x}$, but also on the radial angle with slide axis prolongation. Further, a regression function could be obtained, as shown in

$$
\frac{a_{c x}}{a_{c m}}=\left(\frac{r_{x}}{r_{c m}}\right)^{-1.3 / \sqrt{\cos \theta}},
$$

where $\theta$ was the radial angle with slide axis prolongation.

To sum up, the attenuation of the wave crest amplitude in both meandering and straight reaches was well characterized by a power exponent attenuation. This study was compared to previous studies such as Mohammed and Fritz [35] and Heller and Hager [36], who all thought that the attenuation law of wave crest amplitude could be described as a power function. Given that, these findings were considered to be reliable. Based on these results, the impact of impulse waves on the moored ships will be explored in the next section.

\subsection{The Impact of Impulse Waves on the Moored Ships}

3.2.1. Maximum Mooring Line Tensions. As highlighted in Section 1, the hazardous impact of impulse waves on the moored ships will largely rely on the mooring tension [37]. In present study, the cargo ships were moored by the head and stern lines, which together reacted against the external force impacted by waves. Once any line was broken, the ships would be in danger. Hence, for all 81 tests, the maximum tension of the head and stern line in real world was calculated based on Froude similitude criterion, as shown in Figures 13 and 14. To better analyze the impact, the line's breaking load was also added into the figures, which was $190 \mathrm{kN}$ according to the Load Code for Harbour Engineering (JTS 144-1-2010) [38] issued by the Ministry of Communications of the PRC.

In general, experimental results indicate that in both convex bank and concave bank the mooring tension was greater than the breaking load of the line in most cases. In other words, the moored ships were overall unsafe in the experiments. More specifically, in convex bank, Figure 13 presents the fact that the mooring tensions of the head line and the stern line were nearly equal because the lengths of the head and stern lines were exactly the same. These tensions were much larger than the breaking load of the mooring line in all cases, and the largest mooring tension was about 37 times more than the breaking load.

Similarly, in concave bank, Figure 14 reports that the mooring tension of the head line and the stern line was almost the same, and they were much larger than the breaking load of the mooring line in most cases. However, 


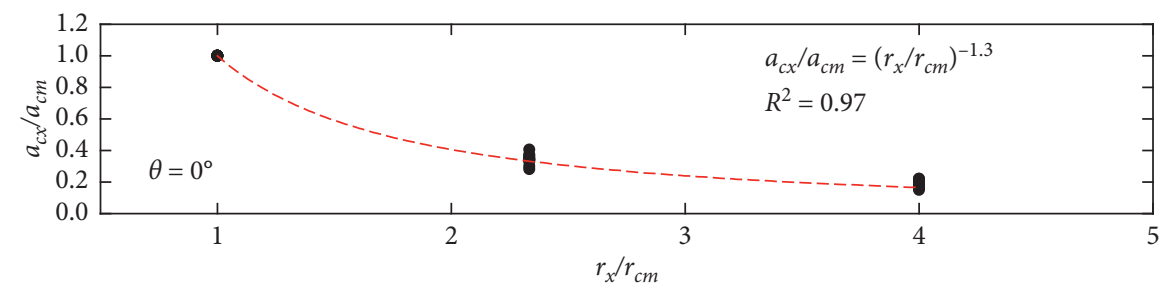

(a)

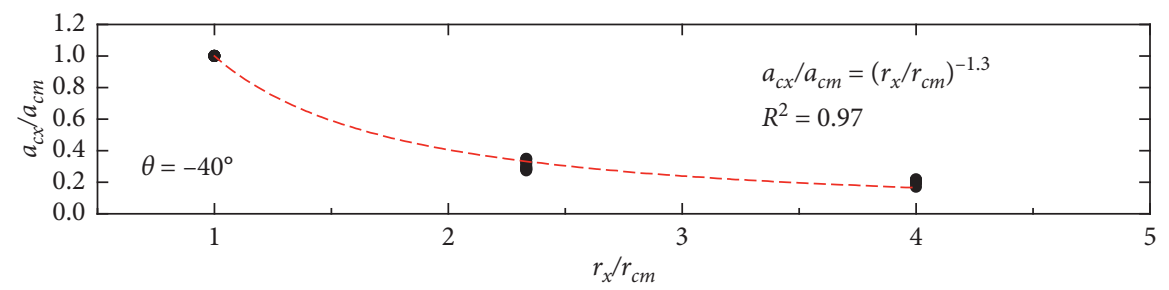

(b)

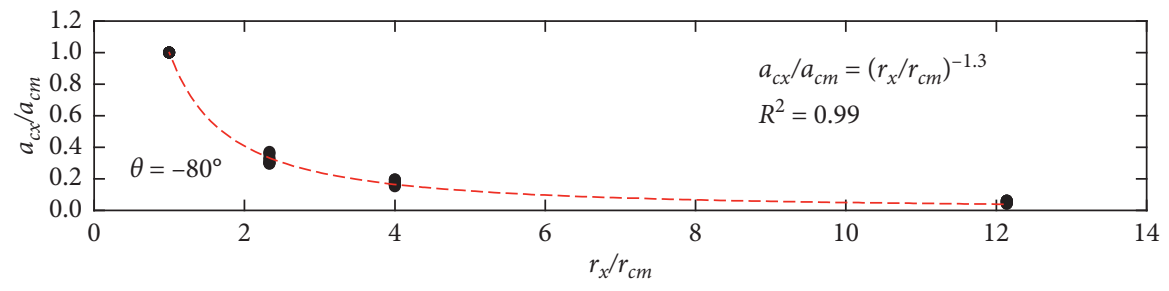

(c)

FIgURE 11: The attenuation law wave crest amplitude in straight reach.

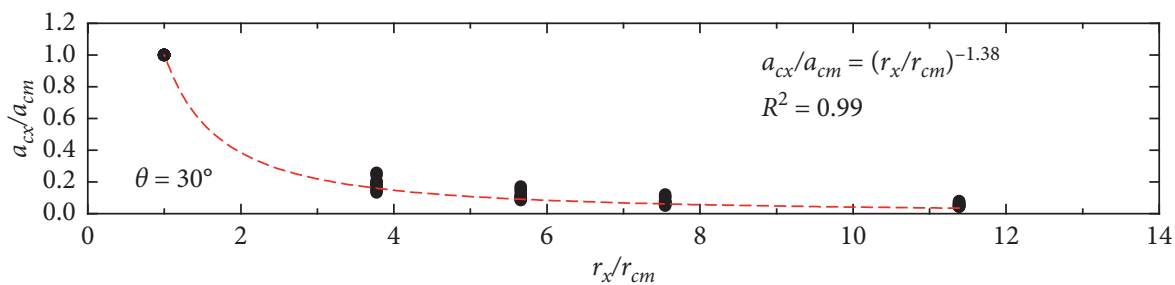

(a)

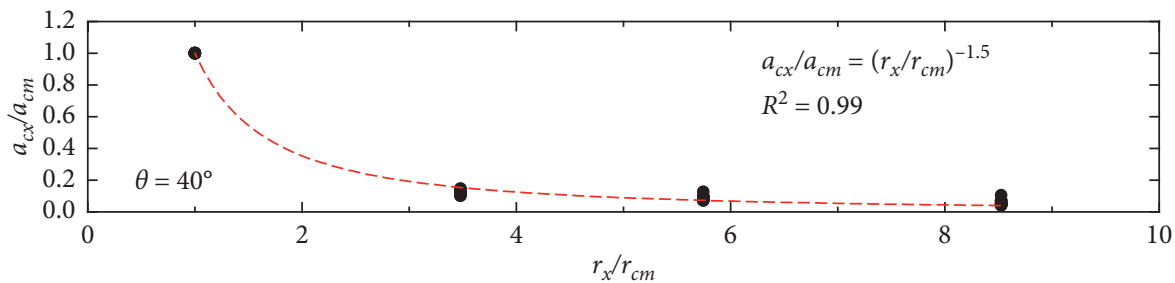

(b)

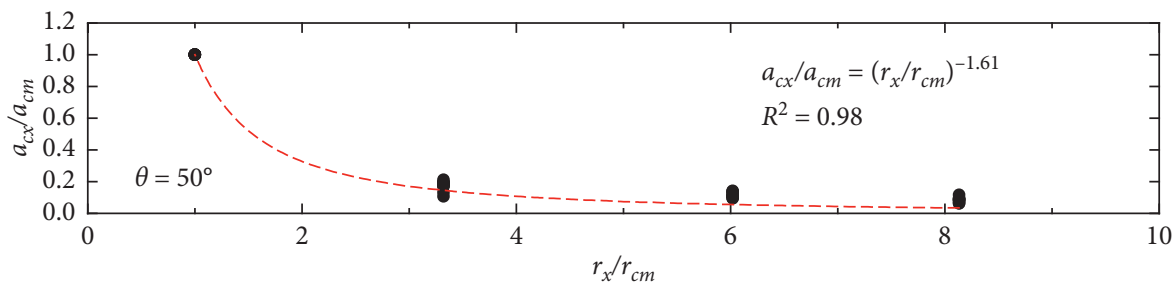

(c)

FIgURe 12: Continued. 


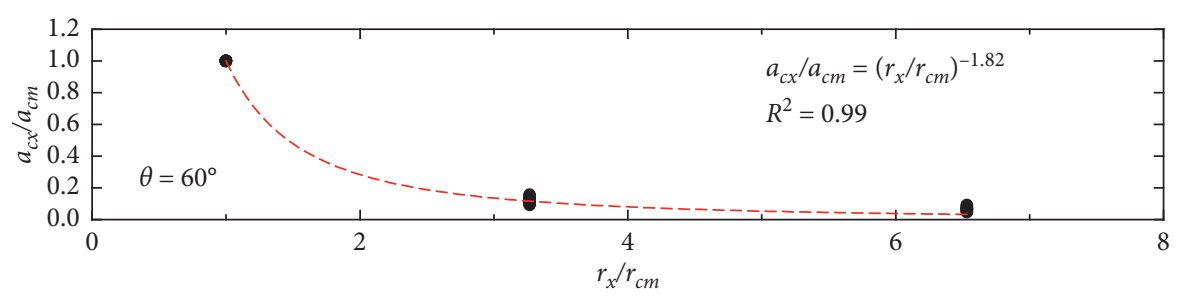

(d)

FIgURE 12: The attenuation law wave crest amplitude in meandering reach.

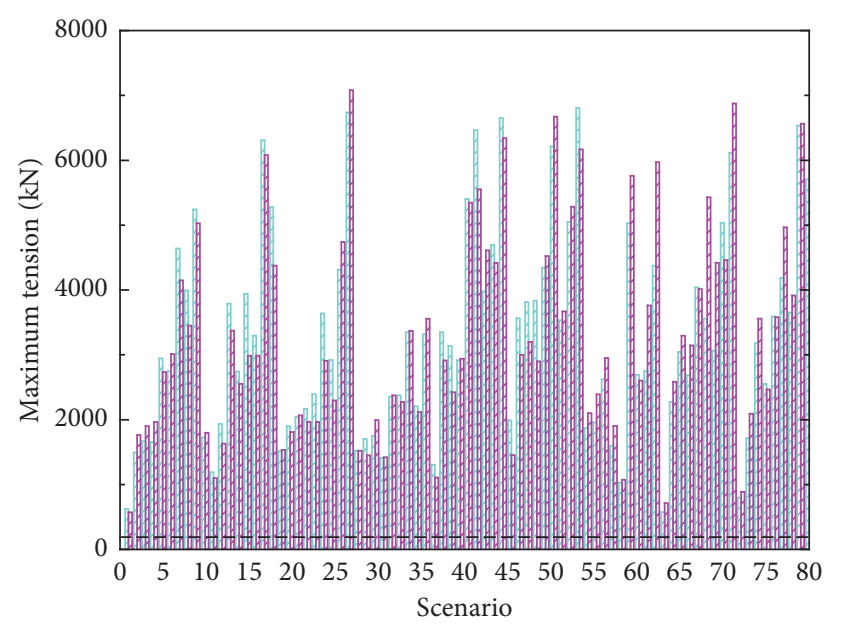

VIJ The tension of the head line

EID The tension of the stern line

--- Breaking load

Figure 13: Maximum line tensions in convex bank.

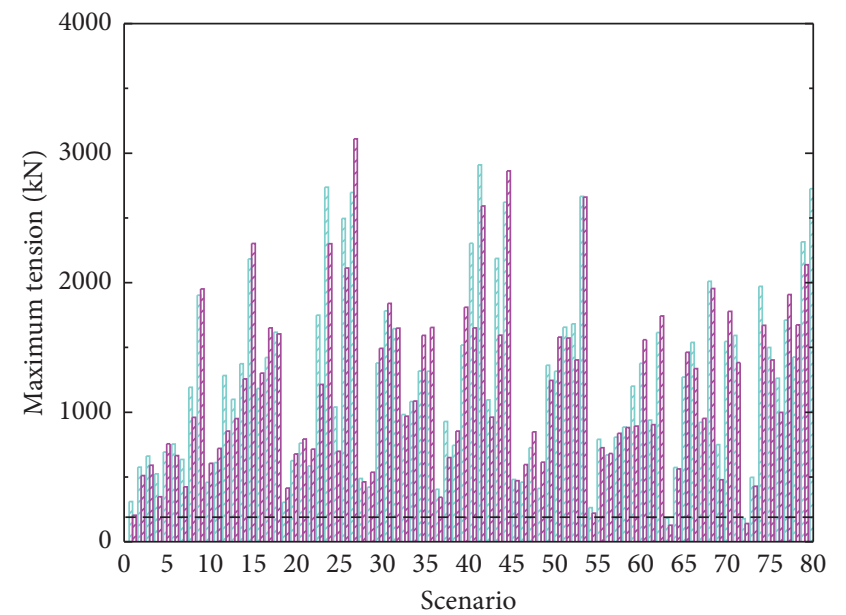

VII The tension of the head line

VII The tension of the stern line

--- Breaking load

FIgURE 14: Maximum line tensions in concave bank.

compared to convex bank, the moored ship cable tension of both head line and stern line in concave bank was smaller. This was mainly due to two reasons: one was that the reflection waves from the wharf increased the wave height in convex bank; the other was the incident angles of the impulse waves, which were parallel to the wharf in concave bank because the impulse wave flowed along it. As a result, the surging was the significant motion of the moored cargo ship against the landslide-generated impulse waves; that is to say, the moored ship moved on wave and primarily moved back and forth. This phenomenon also has been found by Ohgaki et al. [37], who reported the motion of the moored ship against the tsunami. For the moored cargo ship at the wharf of the convex bank, the incident angles of the impulse waves were perpendicular to the quay; hence the swaying was the primary motion of the moored cargo ship.

In a word, the moored ships in the ports were risk of cable breaking in our tests. However, the premise of the conclusion was that the distance between the port and the landslide was a specific value. To evaluate the safety of moored ship further in the distance, the relationship between the mooring tension and the aforementioned wave characteristics should be further revealed. However, considering that wave height and wave amplitude have been linked through (3), only the relationship in wave height was analyzed in next section.

3.2.2. The Relationship between Mooring Tension and Wave Height. At the test site, it was directly observed that the higher the wave height, the greater the mooring tension. On the basis of this experimental phenomenon, by applying the detailed test data, the relationship between mooring tension and wave height is obtained, as shown in Figure 15.

Figure 15 indicates that the relational expressions between the mooring tension and wave height could be expressed as the following, in convex bank and in concave bank, respectively:

$$
\begin{aligned}
& F=1520 H_{m}, \\
& F=960 H_{m},
\end{aligned}
$$

where $F$ was the mooring tension and $R^{2}$ was 0.76 and 0.82 , respectively.

It is understood that the mooring tension could be expressed as a linear function of wave height in both convex bank and concave bank. For this finding, Meng et al. [39] also reported similar result and argued that the relationship between the mooring tension and wave height was approximately linear. In that case, if $H_{m}$ was estimated based 


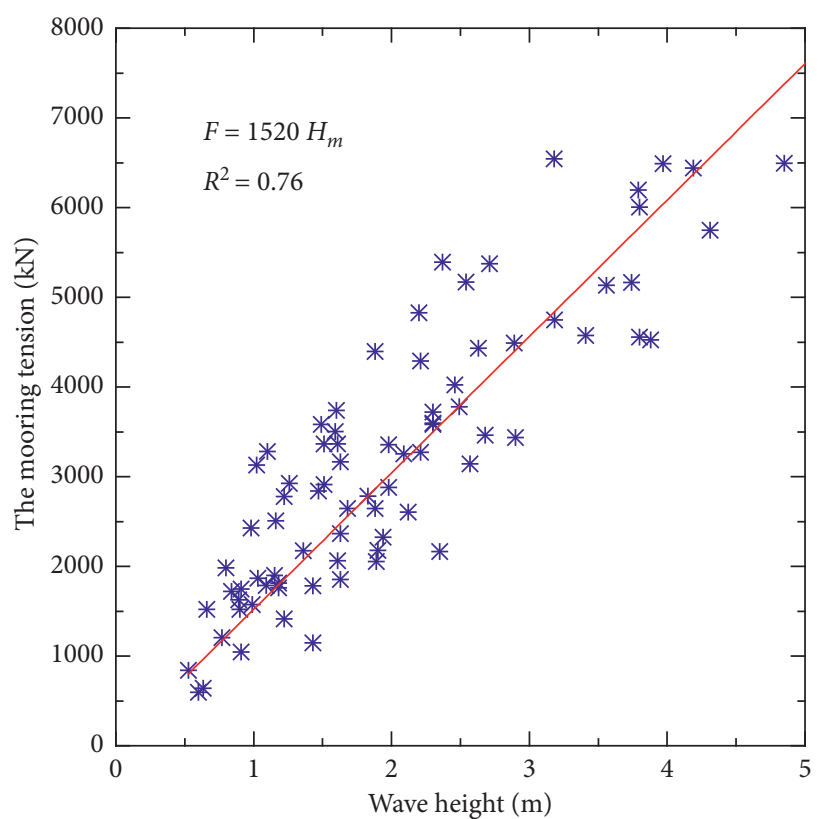

(a)

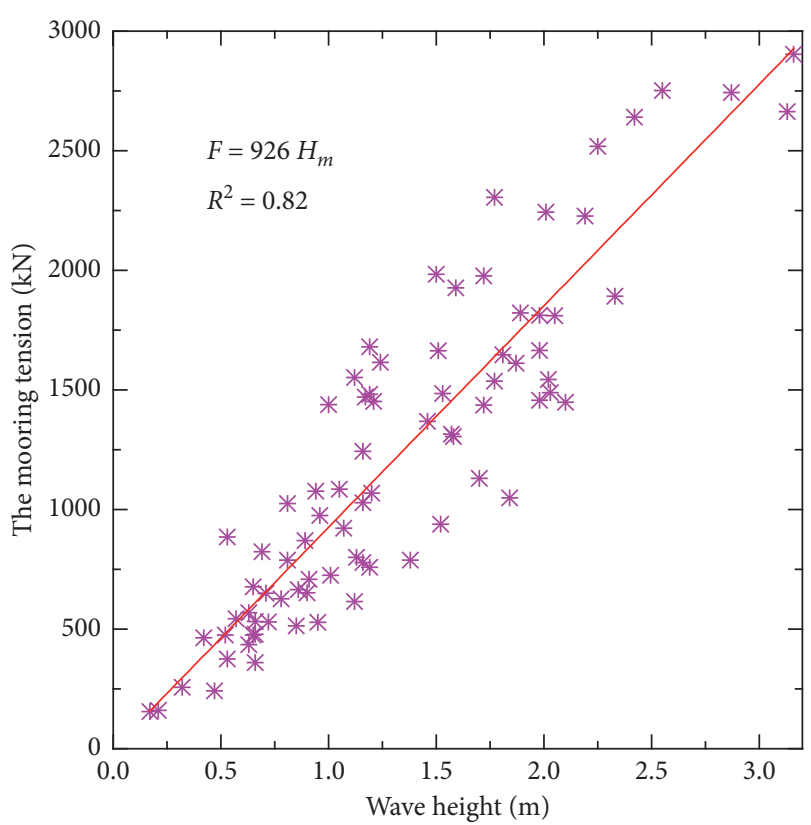

(b)

FiguRE 15: The relationship between mooring tension and wave height: (a) in convex bank and (b) in concave bank.

on (3), the mooring tensions could be calculated according to (6) and (7). Furthermore, when the calculated mooring tension is larger than the breaking load of the mooring line, the moored ship was dangerous. Conversely, the ship was safe.

\section{Conclusions}

To effectively prevent the natural hazard of landslide-generated impulse waves in reservoirs, we examined the hazardous impact on the moored ships in TGR. In detail, threedimensional experiments of impulse waves were used to explore the impulse wave generation, propagation, and its impact on the moored ships. Based on laboratory results, the main conclusions were as follows:

(1) The present experimental results indicate that the impact of impulse waves on the moored ships was mainly due to the first wave amplitude and height, which were attributable to four factors: the slide Froude number, the relative landslide thickness and width, and the still water depth. Unlike the linear regular wave, the relative wave height could be described as an exponential function of the relative wave crest amplitude.

(2) The attenuation of the maximum wave crest amplitude was only attributable to the propagation distance in straight reach. However, the attenuation was influenced by the propagation distance and the radial angle in meandering reach. And both attenuation rules were approximated by a power exponential function.

(3) For the moored cargo ships in the ports, the present experimental results demonstrate that they were unsafe because of the mooring line broken when exposed against the impulse waves generated by landslides. Furthermore, the ship in convex bank was more dangerous than that in concave bank.

(4) The mooring tensions of the head and stern lines were attributable to two factors, i.e., the wave height and the incident angle. Moreover, the mooring tension impacted by the incident angle of 90 deg was larger than that impacted by the incident angle of $0 \mathrm{deg}$. However, the effect on the mooring tension by any other incident angle should be further revealed in future work.

\section{Data Availability}

The data used to support the findings of this study are included herein.

\section{Conflicts of Interest}

The authors declare that they have no conflicts of interest.

\section{Acknowledgments}

This study was supported by the Chongqing Research Program of Basic Research and Frontier Technology (Grant No. cstc2017jcyjBX0070), the Science and Technology Research Program of Chongqing Municipal Education Commission (Grant Nos. KJQN201900718 and KJQN201800737), and China Postdoctoral Science Foundation (Grant No. 2016M592889XB).

\section{References}

[1] S. N. Ward, "Landslide tsunami," Journal of Geophysical Research: Solid Earth, vol. 106, no. B6, pp. 11201-11215, 2001. 
[2] A. Panizzo, P. De Girolamo, and A. Petaccia, "Forecasting impulse waves generated by subaerial landslides," Journal of Geophysical Research: Oceans, vol. 110, no. 12, pp. 1-23, 2005.

[3] S. N. Ward and S. Day, "The 1963 landslide and flood at vaiont reservoir Italy. A tsunami ball simulation," Italian Journal of Geosciences, vol. 130, no. 1, pp. 16-26, 2011.

[4] B. Huang, Y. Yin, and C. Du, "Risk management study on impulse waves generated by Hongyanzi Landslide in Three Gorges reservoir of China on June 24, 2015," Landslides, vol. 13, no. 3, pp. 603-616, 2016.

[5] L. Xiao, S. N. Ward, and J. Wang, "Tsunami squares approach to landslide-generated waves: application to Gongjiafang Landslide, Three Gorges Reservoir, China," Pure and Applied Geophysics, vol. 172, no. 12, pp. 3639-3654, 2015.

[6] B. Huang, S. C. Wang, and Y. B. Zhao, "Impulse waves in reservoirs generated by landslides into shallow water," Coastal Engineering, vol. 123, pp. 52-61, 2017.

[7] H. M. Fritz, W. H. Hager, and H.-E. Minor, "Landslide generated impulse waves," Experiments in Fluids, vol. 35, no. 6, pp. 505-519, 2003.

[8] J. Wang, S. N. Ward, and L. Xiao, "Tsunami squares modelling of the 2015 june 24 hongyanzi landslide generated river tsunami in Three Gorges reservoir, China," Geophysical Journal International, vol. 216, no. 1, pp. 287-295, 2019.

[9] B. Huang, Y. Yin, G. Liu, S. Wang, X. Chen, and Z. Huo, "Analysis of waves generated by Gongjiafang Landslide in $\mathrm{Wu}$ Gorge, Three Gorges Reservoir, on November 23, 2008," Landslides, vol. 9, no. 3, pp. 395-405, 2012.

[10] B. Yang, K. Yin, T. Xiao, L. Chen, and J. Du, “Annual variation of landslide stability under the effect of water level fluctuation and rainfall in the three Gorges Reservoir, China," Environmental Earth Sciences, vol. 76, no. 16, p. 564, 2017.

[11] P. D. LiuTao and L. Junwei, "Analysis of shipping development measures for Yichang to Wuhan section of Yangtze River mainstream," Hydro-Science and Engineering, vol. 1, pp. 76-84, 2019.

[12] P. Wang, L. Han, T. Yu, and C. Meng, "Effects of landslide generated impulse waves on ship impact force for pile wharf," Harbin Gongcheng Daxue Xuebao/Journal of Harbin Engineering University, vol. 37, no. 6, pp. 878-884, 2016.

[13] Z. Cheng, P. Wang, C. Yang, S. Wang, J. Zheng, and Y. Li, "Control mode of waterway traffic under dangerous mountain landslide conditions," Xinan Jiaotong Daxue Xuebao/Journal of Southwest Jiaotong University, vol. 53, no. 4, pp. 748-755, 2018.

[14] P. Yuan, P. Wang, and Y. Zhao, "Model test research on the propagation of tsunamis and their interaction with navigating ships," Applied Sciences, vol. 9, no. 3, p. 475, 2019.

[15] B. Huang, Y. Yin, S. Wang et al., "A physical similarity model of an impulsive wave generated by Gongjiafang Landslide in Three Gorges Reservoir, China," Landslides, vol. 11, no. 3, pp. 513-525, 2014.

[16] E. Noda, "Water waves generated by landslides," Journal of Waterway, Port, Coastal, and Ocean Engineering, vol. 96, no. 4, pp. 835-853, 1970.

[17] J. J. Monaghan and A. Kos, "Scott Russell's wave generator," Physics of Fluids, vol. 12, no. 3, pp. 622-630, 2000.

[18] J. S. Russell, "Report on waves," in Proceedings of the 14th Meeting of the British Association for the Advancement of Science, York, UK, September 1844.

[19] R. L. Wiegel, "Laboratory studies of gravity waves generated by the movement of a submerged body," Transactions, American Geophysical Union, vol. 36, no. 5, pp. 759-774, 1955.
[20] P. Heinrich, "Nonlinear water waves generated by submarine and aerial landslides," Journal of Waterway, Port, Coastal, and Ocean Engineering, vol. 118, no. 3, pp. 249-266, 1992.

[21] G. Sælevik, A. Jensen, and G. Pedersen, "Experimental investigation of impact generated tsunami; related to a potential rock slide, Western Norway," Coastal Engineering, vol. 56, no. 9, pp. 897-906, 2009.

[22] F. Enet and S. T. Grilli, "Experimental study of tsunami generation by three-dimensional rigid underwater landslides," Journal of Waterway, Port, Coastal, and Ocean Engineering, vol. 133, no. 6, pp. 442-454, 2007.

[23] S. Yavari-Ramshe and B. Ataie-Ashtiani, "On the effects of landslide deformability and initial submergence on landslidegenerated waves," Landslides, vol. 16, no. 1, pp. 37-53, 2019.

[24] V. Heller, W. H. Hager, and H.-E. Minor, "Scale effects in Subaerial Landslide generated impulse waves," Experiments in Fluids, vol. 44, no. 5, pp. 691-703, 2008.

[25] H. Chen, Research on the Safety of Vessel Traffic System within the Three Gorges Dam Waters, Wuhan University of Technology, Wuhan, China, 2011.

[26] L. Han and P. Wang, "Prediction of the maximum near-field wave amplitude of impulse waves generated by three-dimensional landslides based on momentum balance," Yanshilixue Yu Gongcheng Xuebao/Chinese Journal of Rock Mechanics and Engineering, vol. 37, no. 11, pp. 2584-2592, 2018.

[27] V. Heller, "Scale effects in physical hydraulic engineering models," Journal of Hydraulic Research, vol. 49, no. 3, pp. 293-306, 2011.

[28] Z. Meng, "Experimental study on impulse waves generated by a viscoplastic material at laboratory scale," Landslides, vol. 15, no. 6, pp. 1173-1182, 2018.

[29] H. M. Fritz, W. H. Hager, and H.-E. Minor, "Near field characteristics of landslide generated impulse waves," Journal of Waterway, Port, Coastal, and Ocean Engineering, vol. 130, no. 6, pp. 287-302, 2004.

[30] F. M. Evers, W. H. Hager, and R. M. Boes, "Spatial impulse wave generation and propagation," Journal of Waterway Port Coastal and Ocean Engineering, vol. 145, no. 3, 2019.

[31] A. Huber and W. H. Hager, "Forecasting impulse waves in reservoirs," in Proceedings of the the 19th Congress On Large Dams C31, Florence, Italy, 1997.

[32] G. Tang, L. Lu, Y. Teng, Z. Zhang, and Z. Xie, "Impulse waves generated by subaerial landslides of combined block mass and granular material," Coastal Engineering, vol. 141, pp. 68-85, 2018.

[33] H. Xue, Q. Ma, M. Diao, and L. Jiang, "Propagation characteristics of subaerial landslide-generated impulse waves," Environmental Fluid Mechanics, vol. 19, no. 1, pp. 203-230, 2018.

[34] F. M. Evers and W. H. Hager, "Generation and spatial propagation of landslide generated impulse waves," in Proceedings of the 35th International Conference on Coastal Engineering, ICCE 2016, Antalya, Turkey, November 2016.

[35] F. Mohammed and H. M. Fritz, "Physical modeling of tsunamis generated by three-dimensional deformable granular landslides," Journal of Geophysical Research: Oceans, vol. 117, no. C11, 2012.

[36] V. Heller and W. H. Hager, "Impulse product parameter in landslide generated impulse waves," Journal of Waterway, Port, Coastal, and Ocean Engineering, vol. 136, no. 3, pp. 145-155, 2010.

[37] K. Ohgaki, H. Yoneyama, and T. Suzuki, "Evaluation on safety of moored ships and mooring systems for a tsunami attack," 
in Proceedings of the OCEANS 2008-MTS/IEEE Kobe Techno-Ocean, Kobe, Japan, April 2008.

[38] JTS 144-1-2010, The Load Code for Harbour Engineering, Ministry of Transport of the People's Republic of China, Beijing, China, 2010.

[39] X. Meng, X. Gao, W. Zhang, and Y. Jiang, "A calculation method of mooring force induced by waves," Journal of Tianjin University, vol. 44, no. 7, pp. 593-596, 2011. 